\title{
Decrease in the prevalence of paediatric adiposity in Switzerland from 2002 to 2007
}

\author{
Isabelle Aeberli ${ }^{1,2, *}$, Rachel S Ammann ${ }^{1}$, Marisa Knabenhans ${ }^{1}$, Luciano Molinari ${ }^{3}$ and \\ Michael B Zimmermann ${ }^{1,4}$ \\ ${ }^{1}$ Human Nutrition Laboratory, Institute of Food Science and Nutrition, ETH Zurich, LFV D1 1, Schmelzbergstrasse \\ 7, CH-8092 Zurich, Switzerland: ${ }^{2}$ Clinic for Endocrinology and Diabetes, University Hospital Zurich, Zurich, \\ Switzerland: ${ }^{3}$ Child Development Center, University Children's Hospital, Zurich, Switzerland: ${ }^{4}$ Division of Human \\ Nutrition, Wageningen University, Wageningen, The Netherlands
}

Submitted 3 December 2008: Accepted 11 August 2009: First published online 22 September 2009

\begin{abstract}
Objective: A national study in Switzerland in 2002 suggested nearly one in five schoolchildren was overweight. Since then, many programmes have been introduced in an attempt to control the problem. The aim of the present study was to determine the prevalence of childhood overweight in Switzerland five years later. Design: In both studies a cross-sectional, three-stage, probability-proportional-tosize cluster sampling of schools throughout Switzerland was used to obtain a representative sample of approximately 2500 children aged 6-13 years. Height and weight were measured and BMI calculated. The BMI references from the Centers for Disease Control and Prevention were used to determine the prevalences of underweight $(<5$ th percentile), overweight $(\geq 85$ th and $<95$ th percentile) and obesity ( $\geq 95$ th percentile).

Results: In 2007 the prevalences of underweight, overweight and obesity in boys were $3.5 \%, 11 \cdot 3 \%$ and $5 \cdot 4 \%$, respectively; in girls they were $2 \cdot 6 \%, 9 \cdot 9 \%$ and $3 \cdot 2 \%$. Compared with 2002, there was a significant decrease in the prevalence of overweight in girls and of obesity in both genders. In contrast to 2002, where there were no differences, in 2007 the prevalence of paediatric obesity was significantly higher in communities with a population $>100000$ compared with smaller communities $(P<0 \cdot 05)$.

Conclusions: In summary, over the past 5 years, the prevalence of adiposity has decreased in Swiss children. These findings suggest that increased awareness combined with mainly school-based programmes aimed at physical activity and healthy nutrition may have helped to control this public health problem. Future monitoring in Switzerland will determine if these findings are sustained.
\end{abstract}

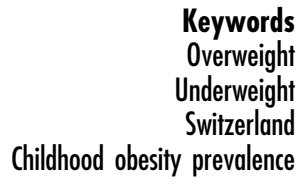

Keywords

Overweight

Switzerland

Childhood obesity prevalence
Over the past few decades, childhood overweight has emerged as an important public health problem worldwide $^{(1-3)}$. In the USA the prevalence of obesity (BMI $\geq 95$ th percentile) in 6- to 11-year-old children has increased from $4 \cdot 2 \%$ in the 1960 s to $18 \cdot 8 \%$ in $2004^{(3,4)}$. Although in most European countries the prevalences are somewhat lower, there have also been dramatic increases over the past few decades $^{(1)}$. Recently, however, several countries including France, Italy and Sweden have reported a stabilization or a decrease in the prevalence of childhood overweight ${ }^{(5-9)}$.

In 2002, the first nationally representative study determining the prevalence of childhood overweight and obesity in Switzerland reported that almost $20 \%$ of primary-school children were overweight and of those over $6 \%$ were obese $^{(10)}$. Compared with regional data from the 1960 s and the 1980s, these numbers represented more than a fivefold increase for the overall overweight prevalence ${ }^{(10)}$.
Since the publication of these data, awareness of the problem in Switzerland has increased and different programmes and initiatives have been launched in order to combat childhood overweight. Therefore the aim of the present follow-up study was to monitor the development of the childhood overweight prevalence and to determine whether the situation has changed over the examined period of 5 years. In addition, the prevalence of underweight was assessed for both time points in order to see whether a change in the prevalence of overweight also affects the rate of underweight.

\section{Subjects and methods}

\section{Subjects}

For both 2002 and 2007, a probability-proportional-to-size cluster sampling based on current census data was used to 
obtain a representative national sample of 2500 Swiss children aged 6-13 years. This sample size represents about one in 250 children in this age group in Switzerland (Swiss Federal Department of Statistics, personal communication). The country was divided into five regions: south (Italian language), north-east (German language), north-west (German language), central east (German language) and west (French language). Furthermore, all communities were grouped into strata by population size: $<10000$, between 10000 and 100000 , and $>100000$ inhabitants. By stratified random selection, sixty schools were identified across Switzerland; the stratification scheme has been described in more detail previously ${ }^{(10)}$. After acceptance of participation of the schools, three or four classes (depending on class sizes) were randomly selected from each school and all students from those classrooms were invited to participate. The average number of participants per school was fortyfive students in 2002 and thirty-eight students in 2007, but it varied according to class sizes and response rate. The data from the study conducted in 2002 have been published elsewhere $^{(10,11)}$.

Ethical approval for both studies was obtained from the Swiss Federal Institute of Technology, Zurich, Switzerland. Written informed consent was obtained from all parents or guardians of the participating children and oral assent was obtained from the children.

\section{Methods}

Before the measurements, which took place over the entire school day, the subjects removed their shoes or slippers as well as pullovers, emptied their pockets and wore only light indoor clothing. Height and weight were measured using standard anthropometric techniques ${ }^{(12)}$. Body weight was measured to the nearest $0 \cdot 1 \mathrm{~kg}$ using a digital scale (BF 18; Breuer, Ulm, Germany) calibrated with standard weights. Height was measured to the nearest $0 \cdot 1 \mathrm{~cm}$ using a portable stadiometer (Seca 214; Seca Medizinische Waagen und Messsysteme, Hamburg, Germany). BMI was calculated as weight divided by the square of height $\left(\mathrm{kg} / \mathrm{m}^{2}\right)$. All measurements were done by the same two trained investigators at each time point; however, the investigators were not the same in 2002 and 2007.

All heads of the schools participating in the study were given a questionnaire to fill out asking about measures taken with regard to increasing physical activity and/or improving nutrition during the past 5 years.

\section{Statistical analysis}

To define underweight, overweight and obesity, the 5th, 85th and 95th BMI-for-age reference percentiles of the Centers for Disease Control and Prevention were used ${ }^{(13)}$; these have previously been validated in Swiss primaryschool children ${ }^{(11)}$. Statistical analysis was performed using SPLUS ${ }^{\circledR} 8 \cdot 0$ Enterprise Developer (Insightful Corporation, Seattle, WA, USA), SPSS for Windows version
16 (SPSS Inc., Chicago, IL, USA) as well as Microsoft ${ }^{\circledR}$ Excel 2003 (Microsoft Corp., Redmond, WA, USA) software packages. The $\chi^{2}$ test was used to check for significant differences between prevalences at the two time points and the $z$ test to check for significant differences between means in 2002 and 2007. The level of significance was set at $0 \cdot 05$.

To analyse for geographic differences, the five clusters that had been used for the sampling (described in detail above) were applied. For demographic differences, the strata by population size (also explained above) were used.

\section{Results}

Basic characteristics of the subjects in both study groups are displayed in Table 1. In the 2002 study, fifty-seven schools accepted to participate in the study; in these schools, 3414 children and their parents were invited to take part in the measurements and 2672 accepted. At the day of measurement sixty-four were absent, which resulted in an overall participation rate of $76 \cdot 4 \%$. After excluding subjects with incomplete data as well as a small number of children aged below 6 or above 13 years, a total of 2431 subjects remained, which consisted of 1196 boys (mean age $9 \cdot 8$ (SE 0.05) years) and 1235 girls (mean age $9 \cdot 8($ se $0 \cdot 05)$ years).

In 2007 , at the sixty schools which accepted to participate in the study, 3188 children and their parents were invited to take part in the examinations. Of these, 2395 accepted to participate, but eighty-five were absent at the day of measurement. The overall response rate was $72 \cdot 5 \%$. After excluding eighty-eight subjects who were either below 6 years of age or above 13 years of age, 2222 children remained. The final sample consisted of 1083 boys (mean age $10 \cdot 0$ (se 0.05$)$ years) and 1139 girls (mean age $10 \cdot 0$ (se $0 \cdot 05)$ years).

Detailed results on the prevalences of overweight and obesity in 2002 have been published elsewhere ${ }^{(10,11)}$. The prevalences of underweight $(<5$ th percentile), overweight ( $\geq 85$ th and $<95$ th percentile) and obesity

Table 1 Basic characteristics of the national samples of Swiss children in 2002 and 2007

\begin{tabular}{|c|c|c|c|c|}
\hline & \multicolumn{2}{|c|}{2002} & \multicolumn{2}{|c|}{2007} \\
\hline $\begin{array}{l}\text { No. of children } \\
\text { Gender ratio (males/females) } \\
\text { No. of schools } \\
\text { Response rate (\%) }\end{array}$ & $\begin{array}{r}24 \\
1196 \\
5 \\
76\end{array}$ & $\begin{array}{l}31 \\
1235 \\
7 \\
\cdot 4\end{array}$ & $\begin{array}{r}22 \\
1083 / \\
6 \\
72\end{array}$ & $\begin{array}{l}22 \\
1139 \\
0 \\
5\end{array}$ \\
\hline Response rate (\%) & Mean & SE & Mean & SE \\
\hline $\begin{array}{l}\text { Age (years) } \\
\text { Weight }(\mathrm{kg}) \\
\text { Height }(\mathrm{m}) \\
\text { BMI }\left(\mathrm{kg} / \mathrm{m}^{2}\right)\end{array}$ & $\begin{array}{c}9 \cdot 8 \\
34 \cdot 8 \\
1 \cdot 389 \\
17 \cdot 7\end{array}$ & $\begin{array}{l}0 \cdot 04 \\
0.20 \\
0.0024 \\
0.06\end{array}$ & $\begin{array}{l}10 \cdot 0^{\star} \\
34 \cdot 8 \\
1 \cdot 401^{*} \\
17 \cdot 4^{*}\end{array}$ & $\begin{array}{l}0 \cdot 04 \\
0 \cdot 20 \\
0 \cdot 0024 \\
0 \cdot 06\end{array}$ \\
\hline
\end{tabular}

${ }^{\star}$ Mean values were significantly different from those in 2002 ( $z$ test): $P<0.05$. 
Table 2 The prevalence of underweight, overweight and obesity in a national sample of Swiss children in the year 2007 by age, using the $\mathrm{CDC} \mathrm{BMI}$ reference criteria

\begin{tabular}{|c|c|c|c|c|c|c|c|c|}
\hline \multirow[b]{2}{*}{ Age } & \multicolumn{2}{|c|}{ BMI $\left(\mathrm{kg} / \mathrm{m}^{2}\right)$} & \multicolumn{2}{|c|}{ Underweight } & \multicolumn{2}{|c|}{ Overweight } & \multicolumn{2}{|c|}{ Obese } \\
\hline & Mean & SE & $\%$ & SE & $\%$ & SE & $\%$ & SE \\
\hline 6 years $(n 57)$ & $15 \cdot 9$ & $0 \cdot 18$ & $1 \cdot 8$ & $1 \cdot 7$ & $17 \cdot 5$ & $5 \cdot 04$ & 0 & \\
\hline 7 years $(n 319)$ & $16 \cdot 3$ & $0 \cdot 12$ & $3 \cdot 4$ & $1 \cdot 02$ & $11 \cdot 3$ & $1 \cdot 77$ & $6 \cdot 3$ & $1 \cdot 36$ \\
\hline 8 years $(n 324)$ & $16 \cdot 5$ & $0 \cdot 11$ & $2 \cdot 5$ & 0.86 & $12 \cdot 0$ & $1 \cdot 81$ & $2 \cdot 2$ & 0.81 \\
\hline 9 years $(n 378)$ & $17 \cdot 2$ & 0.13 & $2 \cdot 6$ & 0.83 & 11.9 & $1 \cdot 67$ & $4 \cdot 5$ & 1.07 \\
\hline 10 years $(n 387)$ & $17 \cdot \overline{6}$ & $0 \cdot 14$ & $2 \cdot 8$ & 0.84 & $8 \cdot 8$ & $1 \cdot 44$ & $4 \cdot 9$ & $1 \cdot 10$ \\
\hline 11 years $(n 355)$ & $18 \cdot 2$ & $0 \cdot 15$ & $5 \cdot 1$ & $1 \cdot 16$ & $11 \cdot 8$ & $1 \cdot 71$ & $4 \cdot 2$ & 1.07 \\
\hline 12 years $(n 402)$ & $18 \cdot 6$ & $0 \cdot 14$ & $2 \cdot 2$ & 0.74 & $8 \cdot 0$ & $1 \cdot 35$ & $4 \cdot 0$ & 0.98 \\
\hline All (n 2222) & $17 \cdot 4$ & 0.06 & 3.06 & 0.37 & $11 \cdot 0$ & 0.66 & $4 \cdot 2$ & 0.40 \\
\hline Boys ( $n$ 1083) & $17 \cdot 5$ & 0.08 & $3 \cdot 51$ & 0.56 & 11.5 & 0.98 & $5 \cdot 26$ & 0.68 \\
\hline Girls ( $n$ 1139) & $17 \cdot 4$ & 0.08 & $2 \cdot 63$ & 0.47 & $10 \cdot 0$ & 0.89 & $3 \cdot 25^{*}$ & 0.53 \\
\hline
\end{tabular}

CDC, Centers for Disease Control and Prevention.

CDC BMI reference criteria ${ }^{(13)}$ : underweight, BMl-for-age $<5$ th percentile; overweight, BMI-for-age $\geq 85$ th and $<95$ th percentile; obese, BMI-for-age $\geq 95$ th percentile.

None of the prevalences were significantly different between the age groups as assessed by the $\chi^{2}$ test.

*Mean value was significantly different from that of boys: $P<0.05$.

( $\geq 95$ th percentile) by age in 2007 are given in Table 2 . The prevalences of underweight, overweight and obesity did not differ significantly between the different age groups. There was no significant gender difference for underweight and overweight children, but the prevalence of obese boys was significantly higher than the prevalence of obese girls $(P<0 \cdot 05)$.

The geographic and demographic differences in underweight, overweight and obesity in 2007 are displayed in Fig. 1. In the study from 2002, no significant geographic or demographic differences had been observed $^{(10)}$. In 2007, however, the prevalence of overweight was highest in the southern region, but the difference reached significance only compared with the central eastern region $(P=0 \cdot 03)$. The prevalence of overweight was significantly higher in the north-western region compared with the central eastern region $(P=0 \cdot 03)$. The geographic differences in the prevalences of underweight or obesity were not significant. The prevalences of both overweight and obesity were higher in communities with a population above 100000 compared with the two smaller categories, but only the difference for obesity prevalence was statistically significant $(P<0 \cdot 05)$.

The prevalences of underweight, overweight and obesity for both time points are displayed in Table 3 . The prevalence of underweight has not changed significantly over the 5 years, but the prevalences of overweight and obesity have decreased. For boys, the decrease in overweight was not significant $(P=0 \cdot 37)$, but for girls it was $(P<0 \cdot 01)$. For obesity, the decrease was significant in both boys $(P=0 \cdot 049)$ and girls $(P<0 \cdot 01)$.

About $60 \%$ of the schools responded to the questionnaire about measures being taken to reduce overweight and obesity. Of these, $83 \%$ said they had initiated a programme emphasizing physical activity and $75 \%$ said they had taken action to encourage healthy eating. The actions taken varied widely; from very basic information (a)

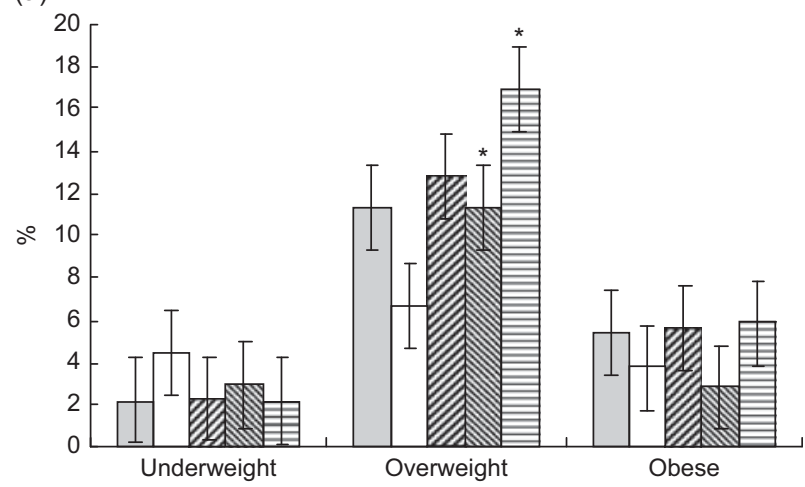

(b)

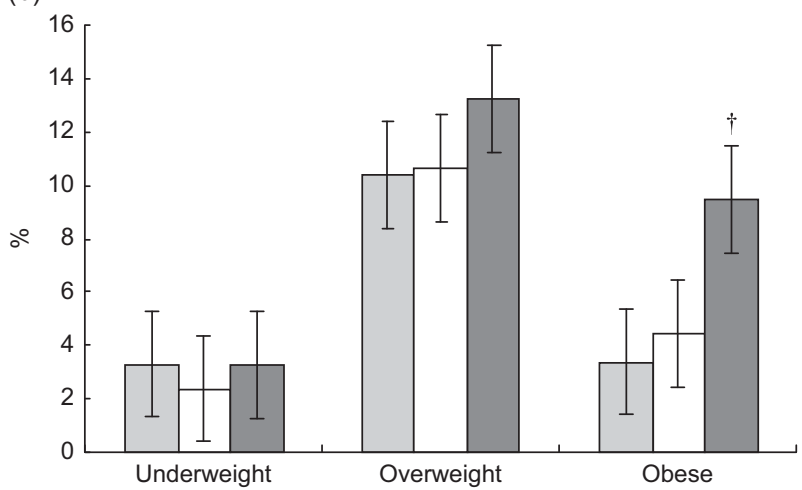

Fig. 1 (a) Geographic $(\square$, west; $\square$, central east; $\mathbb{Z}$, north-west; $\mathbb{N}$, north-east; 目, south) and (b) demographic $(\square,<10000$ inhabitants; $\square$, 10000-100000 inhabitants; $\square,>100000$ inhabitants) differences in the prevalences of underweight, overweight and obesity in a national sample of 6- to 13-year-old children ( $n$ 2222) in Switzerland in 2007, with standard errors represented by vertical bars. *Prevalence was significantly different from that in the central eastern region $(P<0.05)$; †prevalence was significantly different from that in the smaller communities $(P<0.05)$

(such as advising children to walk or cycle to school and bring healthy snacks to school) to more extensive projects lasting weeks or the entire school year. 
Table 3 Prevalence of underweight, overweight and obesity in children in Switzerland in the national studies from 2002 and 2007 by sex using the CDC BMI reference criteria

\begin{tabular}{|c|c|c|c|c|c|c|c|c|}
\hline & \multicolumn{2}{|c|}{ Underweight } & \multicolumn{2}{|c|}{ Overweight } & \multicolumn{2}{|c|}{ Obese } & \multicolumn{2}{|c|}{ Overweight + obesity } \\
\hline & $\%$ & SE & $\%$ & SE & $\%$ & SE & $\%$ & SE \\
\hline \multicolumn{9}{|l|}{2002} \\
\hline Boys & $3 \cdot 0$ & 0.49 & $12 \cdot 5$ & 0.96 & $7 \cdot 4$ & $0 \cdot 80$ & $19 \cdot 9$ & $1 \cdot 19$ \\
\hline Girls & $2 \cdot 7$ & 0.46 & $13 \cdot 2$ & 0.96 & $5 \cdot 7$ & $0 \cdot 71$ & $18 \cdot 9$ & $1 \cdot 12$ \\
\hline \multicolumn{9}{|l|}{2007} \\
\hline Boys & $3 \cdot 5$ & 0.56 & $11 \cdot 5$ & $0 \cdot 98$ & $5 \cdot 3^{*}$ & 0.68 & $16 \cdot 8$ & $1 \cdot 12$ \\
\hline Girls & $2 \cdot 6$ & 0.46 & $10 \cdot 0^{*}$ & 0.89 & $3 \cdot 3^{*}$ & 0.53 & $13 \cdot 3^{*}$ & 0.98 \\
\hline
\end{tabular}

$\mathrm{CDC}$, Centers for Disease Control and Prevention.

CDC BMI reference criteria ${ }^{(13)}$ : underweight, BMI-for-age $<5$ th percentile; overweight, BMI-for-age $\geq 85$ th and $<95$ th percentile;

obese, BMI-for-age $\geq 95$ th percentile; overweight + obesity, all children with BMI-for-age $\geq 85$ th percentile.

${ }^{*}$ Mean values were significantly different from those in 2002 ( $z$ test): $P<0.05$.

\section{Discussion}

Compared with the national study conducted in the year $2002^{(10,11)}$, the present data from 2007 show a decrease in the prevalence of overweight and obesity in both boys and girls. Even though the difference is significant in all but overweight boys, we have to be careful with the interpretation. The procedure for the selection of the schools asked to participate in the study was the same as for the 2002 study, only using more recent census data provided by the Federal Statistical Office. Further, it was ensured in both studies that the sampling scheme was followed very closely. In 2007 it was possible to recruit the appropriate number of schools from each cluster and stratum, while in 2002 three schools were missing. However, those three missing schools were all in different regions and did not represent the same demographic stratum either. Thus, the two samples should be comparable. Although the mean age of the children studied in 2007 was statistically significantly greater than the children studied in 2002, the mean difference was small $(0 \cdot 2$ years $)$ and is unlikely to be relevant for the outcomes of the study, particularly because the prevalences were calculated based on age-specific cut-off points. This difference is likely due to the fact that the sampling period was slightly longer in 2007 compared with 2002. The response rate of the children in 2007 was $73 \%$, slightly below the response rate of $2002(76 \%)$. These $3 \%$ would most probably not influence the result greatly if the children who declined participation were equally distributed over the whole range of body weight; whether this is the case is difficult to judge. Public awareness of the problem of childhood obesity has increased over the past 5 years and this may have caused more parents to consent for their children to participate or, alternatively, may have led some to exclude their overweight children to avoid stigmatization.

Up to 2003, all European countries where data were available had shown increasing prevalences of childhood overweight $^{(1)}$. However, recent reports from several European countries ${ }^{(5-9)}$ and the USA ${ }^{(14)}$ show that childhood obesity prevalences may be levelling off or decreasing slightly over the past few years. In two studies in French children - one sample between 6 and 15 years of age, the other between 7 and 9 years - a stabilization of childhood overweight was observed between 1998 and 2006 and 2000 and 2007, respectively, with a higher prevalence remaining in disadvantaged groups ${ }^{(5,9)}$. Similar trends of stabilization were found in a study analysing data between 1999 and 2003 in 10-year-old children in Stockholm County, Sweden ${ }^{(7)}$; while in Göteborg, Sweden, similar to our study, the prevalence of overweight decreased in 10-year-old girls and was stable in 10-year-old boys between $2000-1$ and $2004-5^{(6)}$.

Compared with 2002, in 2007 we found significant differences in the rates of childhood obesity when comparing communities with populations below and above 100000 inhabitants. In general, comparing the answers received from the schools with regard to measures taken to combat overweight or obesity, we could not discern differences between those from different sized communities. However, it is possible that programmes to increase physical activity have had a bigger impact in more rural areas where children likely have more opportunity to move and play outside, compared with the bigger cities. None of the recent studies reporting a stabilization or decrease in the prevalence of childhood obesity ${ }^{(5-9,14)}$ have analysed their data for demographic changes. The French and one of the Swedish studies ${ }^{(5,7,9)}$ reported that lower socio-economic groups showed a higher overweight prevalence and the US study ${ }^{(14)}$ reported ethnic differences in adiposity. However, we do not have information on either socio-economic or ethnic differences in our sample.

The reported change in paediatric obesity is likely due to an increasing awareness of the public health importance of this topic over the past few years. As a result, a whole range of programmes and projects has been designed and conducted to counteract the alarming increase shown. Although most programmes were rather small and either school- or community-based and not conducted nationwide, it may well be that the accumulation 
of all these programmes has resulted in an overall decrease or at least a stabilization of the prevalence of overweight and obesity in children in Switzerland.

It would go beyond the aim of the present paper to review all the programmes and projects that have been conducted in Switzerland in the past few years; however, a short overview of a selection is given hereafter. First, there are several different clinics as well as other organizations that offer in- or outpatient treatment programmes for obese children and adolescents. Moreover, an important player in the field of overweight prevention and intervention in Switzerland is Suisse Balance, a nationwide initiative financed through the Federal Office of Public Health and the foundation 'Gesundheitsförderung Schweiz', which on its part is sponsored by the cantons of Switzerland as well as different insurance companies. Suisse Balance supports projects and initiatives to promote a healthy lifestyle, more physical activity and well-balanced nutrition. Several projects concentrating on nutrition and physical activity in children have already been launched and some even completed (www.suissebalance.ch). A wide variety of other, mostly smaller programmes and projects is ongoing. A variety of such projects can be found on the website of the 'Schweizerische Netzwerk gesundheitsfördernder Schulen' (http://www.gesunde-schulen.ch/html/projektbrowser.html).

Judging from the questionnaires returned from the participating schools, where over $80 \%$ reported emphasizing physical activity and $75 \%$ healthy eating, the motivation of the schools to do something seems to be rather high. However, as those were all small programmes not conducted under scientific supervision, almost none of them have been validated with respect to their actual impact on the children's weight. We cannot therefore prove any causal effect of these programmes on the decrease in overweight and obesity shown. Further, as the aim of many of the programmes was to change the children's behaviour over the long term in a way that promotes physical activity and/ or teaches the children about a healthy diet, it is even more difficult to evaluate the effect in numbers over a rather short time period. In France, the stabilization of the prevalence of childhood obesity observed in 2006 and 2007, respectively, followed the launch of a Nutrition and Health National Programme established by the government ${ }^{(5,9)}$; however, even there it is not possible to prove a causal relationship between this programme and the stabilization. Similar to Switzerland, no national or regional programme aiming at a reduction in childhood obesity preceded the stabilization of the situation in Sweden, but the increased public awareness of the problem since publication of earlier results is mentioned as a possible factor ${ }^{(6)}$.

Another potentially important factor to control childhood obesity, besides the action being taken by schools and communities, is the relatively strict regulation of Swiss television advertising to children and adolescents. The Swiss Radio and Television Law has included regulations for the protection of children and adolescents from advertising since 1991. However, in the beginning those regulations were not very specific. Since 1997, any advertisement which plays on the credulity of children or the lack of experience of adolescents is prohibited. Since the beginning of 2007, it is now no longer allowed to interrupt children's television programmes by commercials. However, these regulations are not likely to be responsible for the current improvement in the childhood overweight prevalence unless it is assumed that the changes made in 1997 only showed their effects more than 5 years later. But even in general programming, no more than $15 \%$ of daily airtime can be used for advertisements. This limits children's exposure to advertising for energy-dense foods, which in the USA has been shown to be a risk factor for weight gain ${ }^{(15)}$.

Thus, considerable action has been taken in order to combat overweight and obesity in Swiss schoolchildren; this may have contributed to our findings of a lower prevalence. Our findings suggest the increasing prevalence of childhood overweight and obesity in Switzerland until 2002 may be coming under control, although nearly one in six children remains overweight or obese. Thus, treatment programmes should continue to focus on severely obese children and try to reach as many of them as possible, while prevention programmes should focus on the general population. Monitoring and evaluation of the programmes introduced in Switzerland should help to determine which approaches are most effective. However, it seems to be essential to combine healthy eating with increased physical activity in enjoyable ways so that children continue to follow them in their daily routines after they finish school.

\section{Acknowledgements}

The study was financed by the Swiss Federal Office of Public Health. None of the authors had personal or financial conflict of interests regarding the current paper. Each of the authors contributed to the study design and data analysis. Data collection was done by I.A., R.S.A. and M.K. The first draft of the paper was written by I.A. and edited by the other authors. The authors would like to thank the teachers and children at the participating schools for their cooperation.

\section{References}

1. Branca F, Nikogosian H \& Lobstein TJ (2007) The Challenge of Obesity in the WHO European Region and the Strategies for Response. Copenhagen: WHO Regional Office for Europe.

2. Carroquino MJ (2007) Prevalence of Excess Body Weight and Obesity in Children and Adolescents. ENHIS Fact Sheet no. 23. Copenhagen: WHO Regional Office for Europe. 
3. Ogden CL, Carroll MD, Curtin LR, McDowell MA, Tabak CJ \& Flegal KM (2006) Prevalence of overweight and obesity in the United States, 1999-2004. JAMA 295, 1549-1555.

4. Ogden CL, Flegal KM, Carroll MD \& Johnson CL (2002) Prevalence and trends in overweight among US children and adolescents, 1999-2000. JAMA 288, 1728-1732.

5. Peneau S, Salanave B, Maillard-Teyssier L et al. (2009) Prevalence of overweight in 6- to 15-year-old children in central/western France from 1996 to 2006: trends toward stabilization. Int J Obes (Lond) 33, 401-407.

6. Sjoberg A, Lissner L, Albertsson-Wikland K \& Marild S (2008) Recent anthropometric trends among Swedish school children: evidence for decreasing prevalence of overweight in girls. Acta Paediatr 97, 118-123.

7. Sundblom E, Petzold M, Rasmussen F, Callmer E \& Lissner L (2008) Childhood overweight and obesity prevalences levelling off in Stockholm but socioeconomic differences persist. Int J Obes (Lond) 32, 1525-1530.

8. Lazzeri G, Rossi S, Pammolli A, Pilato V, Pozzi T \& Giacchi MV (2008) Underweight and overweight among children and adolescents in Tuscany (Italy). Prevalence and shortterm trends. J Prev Med Hyg 49, 13-21.

9. Salanave B, Peneau S, Rolland-Cachera MF, Hercberg S \& Castetbon K (2009) Stabilization of overweight prevalence in French children between 2000 and 2007. Int J Pediatr Obes 4, 66-72.
10. Zimmermann MB, Gubeli C, Puntener C \& Molinari L (2004) Overweight and obesity in 6-12 year old children in Switzerland. Swiss Med Wkly 134, 523-528.

11. Zimmermann MB, Gubeli C, Puntener C \& Molinari L (2004) Detection of overweight and obesity in a national sample of 6-12-y-old Swiss children: accuracy and validity of reference values for body mass index from the US Centers for Disease Control and Prevention and the International Obesity Task Force. Am J Clin Nutr 79, 838-843.

12. World Health Organization (1995) Physical Status: The Use and Interpretation of Anthropometry. Report of a WHO Expert Committee. WHO Technical Report Series no. 854. Geneva: WHO.

13. Ogden CL, Kuczmarski RJ, Flegal KM, Mei Z, Guo S, Wei R, Grummer-Strawn LM, Curtin LR, Roche AF \& Johnson CL (2002) Centers for Disease Control and Prevention 2000 growth charts for the United States: improvements to the 1977 National Center for Health Statistics version. Pediatrics 109, 45-60.

14. Ogden CL, Carroll MD \& Flegal KM (2008) High body mass index for age among US children and adolescents, 2003-2006. JAMA 299, 2401-2405.

15. Coon KA \& Tucker KL (2002) Television and children's consumption patterns. A review of the literature. Minerva Pediatr 54, 423-436. 